originating from the upper laryngeal nerve, and my experiments have shown that in the dog the irritation of the sympathetic trunk between the lower cervical and first thoracic ganglion, as also of the communicating branches of the brachial plexus, will produce a contraction of the vocal cords of the same side. Beyond these observations the morphological facts mentioned have received no pathological or physiological explanation. I may, in particular, draw attention to the intimate connection before mentioned which exists between the isolated respiratory nerve fibres of the lower laryngeal nerve and the sympathetic and the cardiac branches. The morphological foundation is laid in the above-mentioned facts, showing an exchange of nerve fibres of different origin and destination, but the isolation of these fibres and the investigation of their destinations forms still a subject the difficult solution of which is reserved for future physiological and pathological inquiry.

\title{
A SIMPLIFIED METHOD OF OPERATING FOR DEFLECTION OF THE CARTILAGINOUS SEPTUII.
}

$$
\text { Bi Dundas Grant, M.D., F.R.C.S. }
$$

Since the publication of the description of Moure's operation for deflected septum in the Journil of Laringologr, ${ }^{1}$ it would be strange if those rhinologists who read it had failed to put it in practice, as its principles were bound to appeal to those who had experienced difficulties in the operations previously recommended for its purpose. I have used it in three cases with excellent results.

It will be remembered that, after the shaving off of any prominent thickening ot the cartilaginous septum, the mucous membrane is allowed to heal up, and then-say at an interval of three or four weeks-two cuts are made in the septum, one obliquely upwards and backwards, parallel to the ridge of the nose, the other horizontally, near and parallel to the floor. A somewhat tapering tube, one side of which is made of a slip of soft metal, is introduced into the narrow nostril by means of a pair of expanding forceps; these forceps are then opened so as to press the scptum across into the opposite nostril, the tube is left in situ for a week. and is then removed. In my cases it has caused little or no irritation, has not usually got plugged with clot, and has offered no obstacle to respiration. In some cases nothing further is required, but in others there may be thickenings above and below the position of the tube, which may afterwards be easily diminished by means of the knife.

Of all the methods devised for meeting the difficulty of making a straightened-out septum find room between the fixed points at the

$$
\text { I Vol. xvi., p. } 163 .
$$


extremities of its various diameters, Moure's seems to me the most satisfactory and ingenious. Were the deflected portion square in shape, it would be necessary to make room along a line parallel to one of its vertical boundaries and along one parallel to one of its horizontal boundaries. This is practically what is effected by Moure's cuts, along which a sufficient amount of over-riding takes place to allow room for the straightened septum. The making of these cuts has in his operation to precede the straightening, and with the septum in its deflected position it is not always easy to introduce the eutting shears. I do the operation under nitrous oxide, but the patient is apt to pass out of the anæsthesia as soon as the cuts are made, and before the very excellent nasal tubes can be introduced.

It occurred to me that if I could straighten the septum in the first instance and then make the cuts, the operation would be simplified. If, moreover, it could be possible to omit the use of the nasal tubes (albeit, Moure's are very well borne), a great point would be gained. I recalled to mind a method of straightening and fixing the septal cartilage introduced at least a dozen years ago by an American operator named Roberts-namely, transfixation by means of a strong needle. This, as will be easily realized, is introduced into the nostril and passed through the septum on the concave side anterior to the concavity. Having passed through to the other side, it is then used as a lever to press the convex part into the concave side, and is then passed back through the septum so as to keep it in this position.

In the first of my cases (Miss D-) I used the needle in this way after having made the cuts. There was, of course, a great deal of blood in the nostrils, but the proceeding answered extremely well, in spite of the fact that, owing to the supervention of scarlet fever, I had to remove the needle on the third day. In my next case (that of Elizabeth D-C) I decided to begin by straightening and transfixing with the needle (as in old days) under cocaine, and before making the cuts. This was accomplished without difficulty by means of a strong darning-needle. Gas was then administered, and I was able to introduce the cutting shears with remarkable ease, the septum being almost straight, and to make the "Moure's" incisions, one above and in front of the needle, the other below it. The over-riding was encouraged by means of a little digital manipulation, and the needle was left in situ for a week, a piece of indiarubber tube being placed over it to temper the pressure on the soft parts in front. At the end of a week it was removed, the patient having suffered no discomfort. The breathing through the pre- 
viously obstructed nostril was quite free, and the septum was sufficiently straight, although there was a little thickening above and below the line of the needle.

This method of mine (a combination of portions of two other methods) will, I think, appeal to those who wish a simple plan for dealing with what has hitherto been, to me at least, a very difficult condition to rectify. It consists in:

1. Cocainizing both sides of the septum.

2. Straightening and transfixing with the needle.

3. Administering nitrous oxide gas.

4. Cutting through the cartilage, by means of Moure's shears, horizontally below the deflection, then obliquely in front of and above it parallel to the ridge of the nose, the incisions not meeting below and in front.

5. Manipulating the cartilage at the incisions so as to encourage over-riding.

I need hardly remind you that when the deflection is accompanied by any considerable degree of thickening this should be shaved off beforehand, preferably at an interval of a couple of weeks, though it may be done at the time.

\section{EIGHTH ANNUAL MEETING OF THE AMERICAN LARYNGOLOGICAL, RHINOLOGICAL, AND OTOLO- GICAL SOCIETY.}

Held in Washington, D.C., June 2, 3, and 4, 1902.

Iresident: Charles W. Richardoson, M.D., of Washington, D.C.

First Day-Monday, June 2.

The President, in his address, dwelt upon the methods of teaching the specialities in medical schools. The opinion was expressed that the plan of compelling instruction in the special as well as in the other branches had led to undue crowding of the curriculum, and had been disappointing in its results. The instruction in the specialities, he thought, should be so planned as to supplement rather than to supplant the major branches, of which they form an integral part. Attempts to turn out full-fledged specialists should be promptly checked. Theoretically, the elective system was ideal, yet the tendency in undergraduate life was towards too great narrowing by the elective system, and he thought, in the long-run, 